\title{
Development of SNP-Based Markers to Identify Colletotrichum gossypii in Upland Cotton
}

Hafiz Husnain Nawaz, Hainan Key Laboratory for Sustainable Utilization of Tropical Bioresource, College of Plant Protection, Hainan University, Haikou, Hainan Province, 570228, P.R. China; Usmani Anam, Chinese Academy of Sciences, South China Botanical Garden, Tianhi District, Guangzhou, 510000, Guangdong Province, P.R. China; and M. J. Nelly Rajaofera, Qiguang He, Wenbo Liu, and Weiguo Miao, ${ }^{\dagger}$ Hainan Key Laboratory for Sustainable Utilization of Tropical Bioresource, College of Plant Protection, Hainan University

\begin{abstract}
Colletotrichum gossypii is a causal agent of anthracnose in upland cotton (Gossypii hirsutum). C. gossypii belongs to the C. gloeosporioides species complex. However, the high level of genetic similarity among the species within the C. gloeosporioides species complex makes the development of a diagnostic assay for $C$. gossypii challenging. Furthermore, the spore size and cultural characteristics of $C$. gossypii from different geographical areas can vary. In this study, we examined the morphological variance, growth pattern, and pathogenicity of C. gossypii and developed a molecular diagnostic assay to detect $C$. gossypii in cotton plants from different regions of

China. To overcome any ambiguity in morphological and pathogenic characteristics, a set of primers targeting the $\beta$-tubulin (TUB) gene of $C$. gossypii was designed. Single-nucleotide polymorphisms (SNP) were used to identify $C$. gossypii at the species level using DNA sequence alignments of the TUB gene. The SPSCG/F and SPSCG/R primer pair only amplified C. gossypii, and was able to amplify C. gossypii in mixtures of other Colletotrichum spp., even when DNA concentrations were up to 10 times lower than that of the other species. This is the first report of the development of SNP-based markers for the specific identification of C. gossypii.
\end{abstract}

Colletotrichum spp. are cosmopolitan in distribution and many cause anthracnose in fruit and aerial parts of plants (Phoulivong et al. 2010). These pathogens can severely affect cereals, legumes, ornamentals, vegetables, and fruit trees (Álvarez et al. 2014), causing massive crop destruction in agroclimatic regions, especially, in tropical and subtropical regions (Afanador-Kafuri et al. 2003). In Thailand, Colletotrichum spp. are known to have a wide variety of hosts (Damm et al. 2009), and a host may be infected by multiple Colletotrichum spp. (Hyde et al. 2009). These species are highly adaptable, enabling them to acclimatize to adverse environmental changes (Álvarez et al. 2014). This adaptability can be devastating for the hosts.

Colletotrichum gossypii Southw., one of the most pathogenic asexual species belonging to the $C$. gloeosporioides clade, causes anthracnose in upland cotton (Gossypium hirsutum L.) (Carbone and Kohn 1999). C. gossypii can attack the host plant at any growth stage. A severe attack may damage the whole plant. In younger plants, which are more susceptible to infection than older plants, the pathogen causes physiological damage, resulting in damping off and a reduction in vegetative growth (Botero and Franco 2008). The pathogen is also responsible for minor foliar attacks during the vegetative cycle of cotton in Brazil (Cai et al. 2009). Initially, small reddish-brown necrotic spots appear on the surface of diseased leaves. These spots enlarge rapidly and then blacken over time (Araújo et al. 2003). Symptoms of disease include reduced boll weight, reduced length and thickness of fibers, and abnormal seed weight (Weir et al. 2012).

Commercial cotton seed are not resistant to infection by Colletotrichum spp. (Carbone and Kohn 1999). The distribution of Colletotrichum spp. is of particular concern because the pathogens

${ }^{\dagger}$ Corresponding author: W. Miao; E-mail: miao@hainu.edu.cn

Funding: Agro-scientific Research in the Public Interest (grant number 201403075), Hainan Key Laboratory for Sustainable Utilization of Tropical Bioresource/College of Environment and Plant Protection, Hainan University, and the Hainan Province Government provided financial support.

*The $\boldsymbol{e}$-Xtra logo stands for "electronic extra" and indicates that two supplementary figures and two supplementary tables are published online.

Accepted for publication 7 February 2018.

() 2018 The American Phytopathological Society are thought to be transmitted via seed (Afanador-Kafuri et al. 2014).

A blotter test is usually used to detect $C$. gossypii on seed (Carbone and Kohn 1999); however, identifying Colletotrichum isolates using the blotter test to species level based on their morphological features is unreliable. The precise recognition of an etiological agent of disease helps to improve quarantine regulations and disease risk calculations (Damm et al. 2009). However, the accurate detection of different Colletotrichum spp. is laborious and requires a full understanding of fungal taxonomy. In recent years, molecular detection methods have been developed to overcome these problems, resulting in successful identification (Kück and Meusemann 2010) and characterization of some Colletotrichum spp. (Lima et al. 2012).

A better understanding of the pathogenic variability and host range of Colletotrichum spp. may help to manage the disease more efficiently (Cai et al. 2009). The internal transcribed spacer (ITS) region has been widely used to determine fungal taxonomy. However, phylogenetic investigations based on ITS sequences alone were unable to successfully distinguish different species belonging to the Colletotrichum species complex (Phoulivong et al. 2012). To overcome this problem, phylogenetic analyses involving five genes-actin, $\beta$-tubulin (TUB), calmodulin, glutamine synthetase, and glyceraldehyde-3phosphate dehydrogenase (GAPDH) - in addition to the ITS region have been used to identify some members of the Colletotrichum species complex (Weir et al. 2012).

In this study, we cultured tissue from cotton plants showing symptoms of anthracnose to characterize the morphological variance, growth pattern, and pathogenicity of $C$. gossypii from different regions of China. We also performed a series of experiments to design a rapid and reliable method of identifying $C$. gossypii in cotton using the TUB region. The ability to identify $C$. gossypii within the $C$. gloeosporioides species complex clade should increase our understanding of fungal pathogenicity, which could help us to manage anthracnose in cotton.

\section{Materials and Methods}

Sampling, isolation, and culturing. Diseased tissues of upland cotton (G. hirsutum) exhibiting symptoms of anthracnose were collected from several provinces (Hainan, Xinjiang, and Jiangxi) in China between 2014 and 2016; 89 diseased tissues of infected plants were collected. The lesions of infected plants were chopped into fragments $(0.5 \mathrm{~cm}$ in diameter $)$, surface sterilized in $1 \%$ sodium 
hypochlorite $(\mathrm{NaClO})$ solution for $1 \mathrm{~min}$, followed by a wash with sterile distilled water for $1 \mathrm{~min}$. After drying, the sterilized samples were placed on potato dextrose agar (PDA; Difco Laboratories, Detroit) plates in a sterilized laminar flow hood. The inoculated plates were incubated at $28^{\circ} \mathrm{C}$. When mycelial growth became visible, hyphae from the leading edge of the colony were transferred to fresh PDA medium to obtain a pure culture. Sixty-two isolates were recovered from the diseased samples. Pure cultures of these isolates were stored at $4^{\circ} \mathrm{C}$ until needed.

Morphological studies. The identity of the 62 isolates recovered from the 89 diseased samples was determined by examining cultural characteristics and morphology of 12-day-old colonies, and by molecular analyses. Twenty-seven isolates were identified as C. gossypii (CG01, CG02, CG03, CG04, CG05, CG06, CG07, CG08, CG09, CG10, CG11, CG12, CG13, CG14, CG15, CG16, CG17, CG18, CG19, CG20, CG21, CG22, CG23, CG24, CG25, CG26, and CG27) (O'Donnell and Cigelnik 1997; Shamsi et al. 2015; Templeton et al. 1992; Weir et al. 2012). These 27 isolates were used for further study.

Each of the 27 C. gossypii isolates was subcultured by inoculating Petri dishes of fresh PDA with a single spore. The inoculated plates (three replicates of each isolate) were placed in a $28^{\circ} \mathrm{C}$ incubator with a photoperiod of $12 \mathrm{~h}$ of light and $12 \mathrm{~h}$ of darkness in a randomized complete block design. Fifteen days after incubation, cultures were examined to determine texture, color of the mycelial pad on the upper and lower surface, formation of conidia, and growth pattern. Isolates were classified as having a high, intermediate, or low growth rate based on the extent of growth rate. From 5 days after inoculation, growth rate of the isolates (diameter in millimeters per day) was recorded daily for 20 days. Isolates with 6.0 to $7.1 \mathrm{~mm} \mathrm{day}^{-1}$ were classified as high growth rate, 3.9 to $5.9 \mathrm{~mm} \mathrm{day}^{-1}$ as intermediate, and 1.3 to $4.0 \mathrm{~mm} \mathrm{day}^{-1}$ as low. Conidia were harvested from 15day-old cultures. To characterize appressorial formation, a 30- $\mu$ l conidial suspension was placed in a well of a concave microscope slide, which was placed in a moist chamber overnight to encourage germination. Germinating conidia were observed under a light microscope. The size and shape of the conidia were also recorded and images were obtained using a digital camera. The morphological and cultural characteristics of the $C$. gossypii isolates were compared with a C. gossypii reference strain (HUCG-103) obtained from the Fungal Culture Bank of Hainan University (FCBHU), Haikou, Hainan, China.
The morphological and cultural characteristics of the $C$. gossypii isolates were analyzed and quantified by performing multiple correspondence and principal component analyses. Growth rates were analyzed by analysis of variance (ANOVA). Tukey's multiple range test was used $(\alpha \leq 0.05)$ to identify means that were significantly different from each other.

Pathogenicity tests. Pathogenicity of the 27 isolates of $C$. gossypii was assessed by artificially inoculating susceptible (si main 3 hao) and resistant $(85 y-3)$ cotton cultivars. The leaves were surface sterilized using a $1 \%$ solution of sodium hypochlorite and then washed with sterile distilled water. Mycelial discs from the 27 isolates were excised from the PDA, placed on the leaves, and wrapped with a strip of Parafilm M (Ted Pella, Inc., Redding, CA). Leaves inoculated with sterile PDA discs served as a control. The leaves were incubated in covered transparent plastic trays containing $1 \mathrm{~cm}$ of water to provide humidity. The leaves were placed in small plastic dishes that floated on the water. The trays were placed in a $22^{\circ} \mathrm{C}$ incubator with a photoperiod of $12 \mathrm{~h}$ of light and $12 \mathrm{~h}$ of darkness. From 5 days after inoculation, the lesion area (length by width in millimeters) was measured daily for 20 days. There were three replicates of each treatment. The mean lesion area for each treatment was recorded daily to calculate the area under the disease progress curve (AUDPC-days) using the trapezoidal method (Emge and Shrum 1976). The pathogenicity of each of the 27 isolates and the reference strain (HUCG-103) was expressed as the mean AUDPC-days \pm the standard deviation. Data were analyzed by ANOVA. Tukey's range test was used to assess significant differences at $\alpha \leq 0.05$ (Fig. 1).

DNA isolation and purification. Liquid cultures of the 27 isolates were grown in $100 \mathrm{ml}$ of potato dextrose broth in Erlenmeyer flasks and incubated for 10 days at $28^{\circ} \mathrm{C}$ under constant artificial light. DNA was extracted and purified using the E.Z.N.A. Fungal DNA Mini Kit (Omega Bio-Tek, Inc., Norcross, GA). DNA quality was checked by $0.8 \%$ (wt/vol) agarose gel electrophoresis; the gel was stained with ethidium bromide and the DNA bands were visualized under UV light. Extracted DNA was stored at $-20^{\circ} \mathrm{C}$ until further use.

Polymerase chain reaction amplification. To confirm the molecular identification of the $C$. gossypii isolates, the ITS region and the TUB and GAPDH genes were amplified (O'Donnell and Cigelnik 1997; Templeton et al. 1992; Weir et al. 2012). ITS (accession number JX844098.1), TUB (accession number JX844123.1), and GAPDH

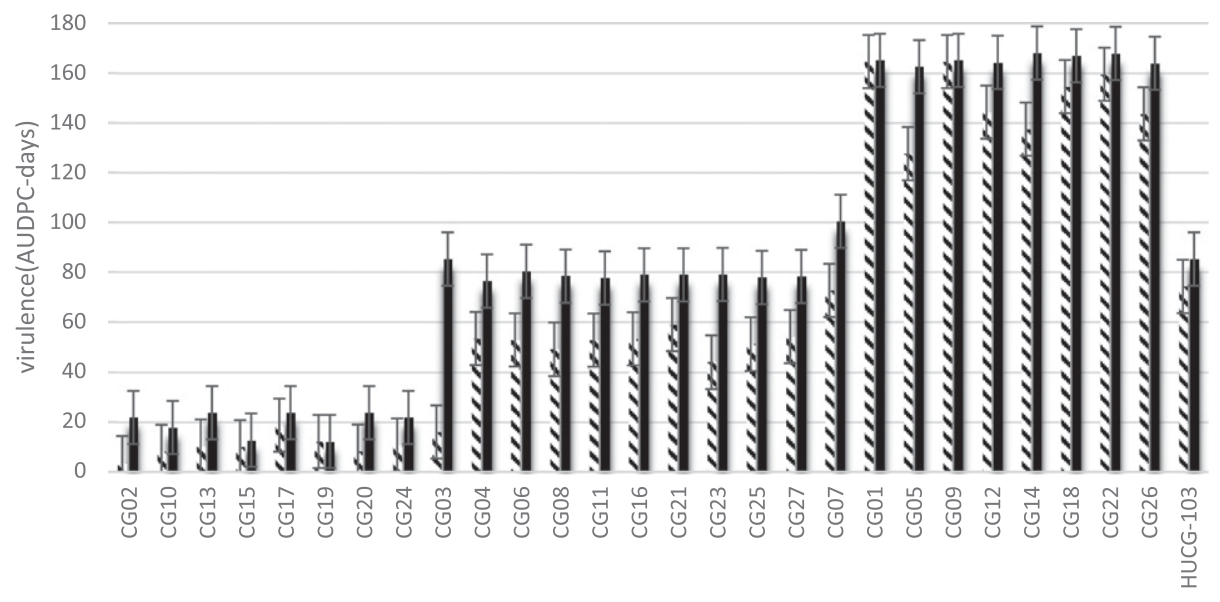

C. gossypii strains

$\checkmark$ resistant cotton leaves a susceptible cotton leaves

Fig. 1. Virulence of Colletotrichum gossypii isolates on leaves of susceptible (si main 3 hao) and resistant (85y-3) cultivars of cotton (Gossypium hirsutum). Virulence of the C. gossypii isolates was evaluated using the area under the disease progress curve (AUDPC-days). Values shown represent the mean AUDPC-days \pm standard deviation. Low AUDPC-days values indicate that the $C$. gossypii isolate has a low level of virulence whereas high AUDPC-days values indicate a high level of virulence (i.e., that the cotton leaves were highly susceptible to anthracnose). Striped bars represent virulence toward the resistant cultivar and solid black bars represent virulence toward the susceptible cultivar. HUCG-103 is a reference C. gossypii isolate. 
(accession number JX847016.1) sequences previously uploaded to GenBank were used as reference sequences and to design new primers for previously described regions.

Primer pairs ITS1 (GATTTAACGACGTTTCTTCTG) and ITS4 (GTCCGCCACTACCTTTGAG) were used to amplify the ITS region, TUB5 (CGATGAAGAACGCAGCGAAAT) and TUB6 (GGCGGTCTACGGCAAGAGT) were used to amplify the TUB gene

Table 1. Colletotrichum gloeosporioides species complex isolates used to check the specificity of the primers ${ }^{\mathrm{w}}$

\begin{tabular}{|c|c|c|c|c|}
\hline $\begin{array}{l}\text { Isolate } \\
\text { number }\end{array}$ & Species & ITS $^{x}$ & TUB $^{\mathbf{y}}$ & SPSCG $^{\mathbf{z}}$ \\
\hline 1 & C. gossypii & + & + & + \\
\hline 2 & C. gossypii & + & + & + \\
\hline 3 & C. gossypii & + & + & + \\
\hline 4 & C. gossypii & + & + & + \\
\hline 5 & C. gossypii & + & + & + \\
\hline 6 & C. gossypii & + & + & + \\
\hline 7 & C. gossypii & + & + & + \\
\hline 8 & C. gossypii & + & + & + \\
\hline 9 & C. gossypii & + & + & + \\
\hline 10 & C. gossypii & + & + & + \\
\hline 11 & C. gossypii & + & + & + \\
\hline 12 & C. gossypii & + & + & + \\
\hline 13 & C. gossypii & + & + & + \\
\hline 14 & C. gossypii & + & + & + \\
\hline 15 & C. gossypii & + & + & + \\
\hline 16 & C. gossypii & + & + & + \\
\hline 17 & C. gossypii & + & + & + \\
\hline 18 & C. gossypii & + & + & + \\
\hline 19 & C. gossypii & + & + & + \\
\hline 20 & C. gossypii & + & + & + \\
\hline 21 & C. gossypii & + & + & + \\
\hline 22 & C. gossypii & + & + & + \\
\hline 23 & C. gossypii & + & + & + \\
\hline 24 & C. gossypii & + & + & + \\
\hline 25 & C. gossypii & + & + & + \\
\hline 26 & C. gossypii & + & + & + \\
\hline 27 & C. gossypii & + & + & + \\
\hline 28 & C. gossypii (HUCG-103) & + & + & + \\
\hline 29 & C. gloeosporioides & + & - & + \\
\hline 30 & C. gloeosporioides & + & + & - \\
\hline 31 & C. gloeosporioides & + & - & - \\
\hline 32 & C. gloeosporioides & + & + & - \\
\hline 33 & C. gloeosporioides & + & + & - \\
\hline 34 & C. fructicola & + & - & - \\
\hline 35 & C. fructicola & + & - & - \\
\hline 36 & C. fructicola & + & + & - \\
\hline 37 & C. gossypii var. cephalosporioides & + & + & - \\
\hline 38 & C. gossypii var. cephalosporioides & + & + & - \\
\hline 39 & C. gossypii var. cephalosporioides & + & + & - \\
\hline 40 & C. gossypii var. cephalosporioides & + & + & - \\
\hline 41 & C. gossypii var. cephalosporioides & + & + & - \\
\hline 42 & C. gossypii var. cephalosporioides & + & + & - \\
\hline 43 & C. siamense & + & + & - \\
\hline 44 & C. siamense & + & + & - \\
\hline 45 & C. queenslandicum & + & + & - \\
\hline 46 & C. musae & + & + & - \\
\hline 47 & C. tropicale & + & + & - \\
\hline 48 & C. tropicale & + & + & - \\
\hline 49 & Colletotrichum sp. & - & + & - \\
\hline 50 & Colletotrichum sp. & + & + & - \\
\hline 51 & C. queenslandicum & + & - & - \\
\hline
\end{tabular}

" Symbols: + and - indicate that the isolate was and was not amplified, respectively.

x ITS = internal transcribed spacer; primers ITS1 and ITS4 were used to amplify the ITS region.

y TUB $=\beta$-tubulin; TUB5 and TUB6 were used to amplify the TUB region.

${ }^{\mathrm{z}} \mathrm{SPSCG}=C$. gossypii -specific primer; SPSCG/F and SPSCG/R were used to amplify the TUB region. region, and GAP1 (CCCTCCAAACTCGCCACTAC) and GAP4 (CATCACCGCTCAAACCTCCC) were used to amplify the GAPDH gene region (BGI Genomics InL, Shenzhen, China). With these primers, the expected product sizes were $450 \mathrm{bp}$ for the ITS region, $460 \mathrm{bp}$ for the TUB gene region, and $250 \mathrm{bp}$ for the GAPDH gene region. Polymerase chain reaction (PCR) was performed in a $25.5-\mu 1$ reaction containing $1 \mu l$ of genomic DNA, $1 \mu l$ of forward primer, $1 \mu l$ of reverse primer, $10 \mu l$ of deionized water, and $12.5 \mu l$ of $2 \times$ Eco Taq Supermix (Thermo Fisher Scientific Inc., Waltham, MA). DNA amplification was performed in a GeneAmp 9700 DNA thermal cycler (PerkinElmer Inc., Waltham, MA). The initial denaturation was carried out at $95^{\circ} \mathrm{C}$ for $1 \mathrm{~min}$ followed by 36 cycles of denaturation at $94^{\circ} \mathrm{C}$ for $1 \mathrm{~min}$, annealing at $58^{\circ} \mathrm{C}$ for $1 \mathrm{~min}$, and extension at $72^{\circ} \mathrm{C}$ for $1 \mathrm{~min}$. A final extension was performed at $72^{\circ} \mathrm{C}$ for $10 \mathrm{~min}$. The PCR products were analyzed by electrophoresis on a $0.8 \%$ (wt/vol) agarose gel. A 2,000-bp DNA ladder (Sigma-Aldrich, St. Louis) was used as a molecular weight standard. The gel was stained with ethidium bromide, observed under UV light, and photographed. The PCR products were then purified using an E.N.Z.A Gel Extraction Kit (Omega Bio-Tek, Inc.) and sequenced by Sanger sequencing (BGI Genomics InL).

The MEGA6 software program was used for alignment and other sequence comparison tests (Tamura et al. 2013). The TUB gene sequences of the isolated $C$. gossypii isolates were compared with 82 TUB reference sequences of Colletotrichum spp., including C. gossypii and C. gossypii var. cephalosporioides, obtained from the GenBank database (accession numbers are shown in Supplementary Table S1).

Design of $C$. gossypii-specific PCR primers. To design C. gossypiispecific primers to detect $C$. gossypii using the TUB gene region, we compared the TUB sequences of the $C$. gossypii isolates from China with those of the TUB sequences of 77 Colletotrichum spp. previously submitted to the GenBank database. The MEGA6 alignment software program was used to align multiple sequences (Tamura et al. 2013). We focused on single-nucleotide differences because of the frequency difference between the $C$. gossypii isolates and the sequences of the 77 Colletotrichum spp. These single-nucleotide differences were used to design primers that could only amplify the $C$. gossypii TUB region. A species-specific primer pair, SPSCG/F (5'-ATGGAACAGG CAAAACATTTCTG-3') and SPSCG/R (3'-ACGGCGTCCAT GGTACCG-5'), was prepared using the Primer Premier 5 software (www.PremierBiosoft.com). The single-nucleotide difference was put at the $5^{\prime}$ end of the forward primer. The specificity of the species-specific primer was confirmed by PCR using the DNA template of different Colletotrichum spp. These Colletotrichum spp. were arranged with the help of different regional molecular laboratories in China and the FCBHU.

PCR-based DNA amplification using SPSCG/F and SPSCG/ $\mathbf{R}$ primers. The SPSCG/F and SPSCG/R primers were used to amplify the TUB region of the studied isolates. PCR was performed as described above. The specificity of the primers was tested against the genomic DNA of $C$. gossypii isolates, the $C$. gloeosporioides species complex, and different fungal species.

Specificity of primers and sensitivity of PCR. The ITS1/ITS4 and TUB5/TUB6 primer pairs and the C. gossypii-specific primer pair SPSCG/F and SPSCG/R were tested against the genomic DNA of 51 fungal species belonging to the $C$. gloeosporioides species complex to test for cross reactions with nontarget fungal species (28 isolates of C. gossypii, 5 isolates of $C$. gloeosporioides, 3 isolates of $C$. fructicola, 6 isolates of $C$. gossypii var. cephalosporioides, 2 isolates of $C$. siamense, 2 isolates of $C$. queenslandicum, 1 isolates of $C$. musae, 2 isolates of C. tropicale, and 2 isolates of Colletotrichum spp.) (Table 1). The specificity and sensitivity of the primer pair SPSCG/F and SPSCG/R was assessed by attempting to amplify 1:1 DNA mixtures comprising $1.067 \mathrm{ng}$ of $C$. gossypii DNA and $1.079 \mathrm{ng}$ of C. gloeosporioides DNA, 1:1 DNA mixtures comprising $1.067 \mathrm{ng}$ of C. gossypii DNA and 1.068 ng of $C$. fructicola DNA, and 1:1:1 DNA mixtures comprising $1.067 \mathrm{ng}$ of $C$. gossypii DNA, $1.079 \mathrm{ng}$ of C. gloeosporioides DNA, and $1.068 \mathrm{ng}$ of $C$. fructicola DNA using the SPSCG/F and SPSCG/R primer pair (Hübschen et al. 2004). The sensitivity of the primer pair SPSCG/F and SPSCG/R was 
further assessed by attempting to amplify 1:2, 1:5, and 1:10 DNA mixtures of C. gossypii with C. gloeosporioides and with C. gossypii with $C$. fructicola (the DNA concentrations used in the DNA mixtures are listed in Supplementary Table S2). To cross check the specificity of the $C$. gossypii-specific primer pair, we attempted to amplify C. gossypii, C. fructicola, and C. gloeosporioides separately using the SPSCG/F and SPSCG/R primer pair, which served as controls. DNA amplification was performed using PCR, as described above. The PCR products were analyzed by electrophoresis on a $0.8 \%$ (wt/vol) agarose gel. A 2,000-bp DNA ladder (Sigma-Aldrich) was used as a molecular weight standard. The gel was stained using ethidium bromide, observed under UV light, and photographed. PCR amplification was repeated thrice to check the consistency of the results obtained.

DNA modeling and phylogenetic analysis. The consensus sequence was assembled using MEGA6 software. For comparative purposes, closely related DNA sequences of the TUB gene region of species belonging to the $C$. gloeosporioides species complex were obtained from GenBank, and sequence alignment was performed using the MUSCLE algorithm implemented in MEGA6 (Tamura et al. 2013). The DNA sample with the minimum Bayesian information criterion (BIC) value is expected to have the best substitution pattern. In this analysis, more than 50 nucleotide sequences were used for the construction of maximum-likelihood phylogenetic trees. For Bayesian inference of the phylogenetic reconstruction, the TUB sequence data were used to construct two phylogenetic trees (Ronquist et al. 2012).

\section{Results}

Strain isolation. Symptoms of anthracnose were observed on cotton leaves and cotton bolls of infected samples collected from cotton fields in three Chinese provinces (Hainan, Xinjiang, and Jiangxi). The pathogen was found mostly on leaves in the form of reddishbrown spots whereas, on cotton bolls, the infection appeared as blackish necrotic lesions. Initially, 62 fungal isolates were collected from the field. However, after molecular and morphological screening, 27 isolates were identified as C. gossypii: CG01, CG02, CG03, CG04, CG05, CG06, CG07, CG08, CG09, CG10, CG11, CG12, CG13, CG14, CG15, CG16, CG17, CG18, CG19, CG20, CG21, CG22, CG23, CG24, CG25, CG26, and CG27.

Morphological study of $\boldsymbol{C}$. gossypii isolates. Most of the C. gossypii isolates formed colonies with uniform or irregular edges. Both the aerial mycelium and the mycelium visible on the underside of the cultures appeared white to light-gray in color. Sporulation occurred with all isolates and spores were usually observed at the center of the colony. The spores were reddish yellow to salmon pink. Most conidia were oblong to elliptical shaped. Elliptical-fusiform and elliptical shapes were also detected. On PDA medium, perithecia of colonies that were more than 20 days old were hard and dark brown to black in color. Perithecia were either distributed unevenly

Table 2. Morphological, cultural, and pathogenic characterization of Colletotrichum gossypii isolates ${ }^{\mathrm{v}}$

\begin{tabular}{|c|c|c|c|c|c|c|c|c|}
\hline \multirow[b]{2}{*}{ Isolate } & \multirow[b]{2}{*}{ Infected } & \multicolumn{3}{|c|}{ Conidia } & \multirow[b]{2}{*}{ Typey } & \multirow[b]{2}{*}{ Growth ${ }^{z}$} & \multicolumn{2}{|c|}{ AUDPC } \\
\hline & & Shape $^{x}$ & Length $(\mu \mathrm{m})$ & Width $(\mu \mathrm{m})$ & & & Susc & Res \\
\hline CG01 & Cotton bolls & Oblong & $10.67 \mathrm{a}$ & $3.1 \mathrm{c}$ & A & $6.27 \mathrm{a}$ & $165.13 \mathrm{a}$ & $164.6 \mathrm{a}$ \\
\hline CG02 & Cotton bolls & Oblong & $10.13 \mathrm{efg}$ & $2.76 \mathrm{kl}$ & $\mathrm{B}$ & $3.87 \mathrm{o}$ & $3.16 \mathrm{~h}$ & $3.67 \mathrm{~g}$ \\
\hline CG03 & Leaves & Oblong & $10.60 \mathrm{ab}$ & $3.2 \mathrm{~b}$ & B & $4.27 \mathrm{~lm}$ & $25.42 \mathrm{e}$ & $16 \mathrm{~g}$ \\
\hline CG04 & Cotton bolls & Oblong & $10.43 \mathrm{bc}$ & $2.9 \mathrm{e}$ & $\mathrm{E}$ & $4.70 \mathrm{i}$ & $76.42 \mathrm{~d}$ & $53.33 \mathrm{f}$ \\
\hline CG05 & Leaves & Oblong & $10.66 \mathrm{a}$ & $2.80 \mathrm{gh}$ & $\mathrm{B}$ & $4.70 \mathrm{i}$ & $162.54 \mathrm{a}$ & $127.6 \mathrm{~d}$ \\
\hline CG07 & Leaves & Oblong & $9.43 \mathrm{k}$ & 2.76 ghijk & $\mathrm{D}$ & $3.30 \mathrm{p}$ & $100.4 \mathrm{~b}$ & $72.67 \mathrm{e}$ \\
\hline CG09 & Leaves & Oblong & $10.13 \mathrm{efg}$ & $2.81 \mathrm{fg}$ & B & $4.86 \mathrm{~g}$ & $165.13 \mathrm{a}$ & $164.6 \mathrm{a}$ \\
\hline CG11 & Leaves & Oblong & $9.97 \mathrm{gh}$ & $2.73 \mathrm{ijkl}$ & $\mathrm{B}$ & $4.57 \mathrm{k}$ & $77.64 \mathrm{~d}$ & $52.67 \mathrm{f}$ \\
\hline CG16 & Leaves & Oblong & $10.13 \mathrm{efg}$ & 2.75 ghijk & B & $5.28 \mathrm{f}$ & $78.92 \mathrm{~cd}$ & $53.18 \mathrm{f}$ \\
\hline $\mathrm{CG} 20$ & Leaves & Oblong & $10.35 \mathrm{~cd}$ & $2.87 \mathrm{ef}$ & A & $6.27 \mathrm{a}$ & 23.75 ef & $8.35 \mathrm{~g}$ \\
\hline CG21 & Leaves & Oblong & $10.11 \mathrm{efg}$ & 2.661 & $\mathrm{C}$ & $5.95 \mathrm{~b}$ & $78.92 \mathrm{~cd}$ & $58.95 \mathrm{ef}$ \\
\hline CG22 & Cotton bolls & Oblong & $10.13 \mathrm{efg}$ & $2.71 \mathrm{jkl}$ & $\mathrm{C}$ & $5.73 \mathrm{c}$ & $167.89 \mathrm{a}$ & $159.52 \mathrm{ab}$ \\
\hline $\mathrm{CG} 23$ & Cotton bolls & Oblong & $9.78 \mathrm{ij}$ & 2.76 ghijk & $\mathrm{D}$ & $4.21 \mathrm{~m}$ & $79.04 \mathrm{~cd}$ & $43.93 \mathrm{f}$ \\
\hline CG24 & Cotton bolls & Oblong & $10.45 \mathrm{bc}$ & $3.22 \mathrm{ab}$ & A & $6.27 \mathrm{a}$ & 21.85 ef & $10.82 \mathrm{~g}$ \\
\hline CG25 & Cotton bolls & Oblong & $10.69 \mathrm{a}$ & $3.27 \mathrm{a}$ & A & $6.27 \mathrm{a}$ & $77.85 \mathrm{~d}$ & $51.17 \mathrm{f}$ \\
\hline CG26 & Cotton bolls & Oblong & $9.63 \mathrm{j}$ & 2.74 hijk & $\mathrm{C}$ & $4.08 \mathrm{n}$ & $163.97 \mathrm{a}$ & $143.63 \mathrm{bcd}$ \\
\hline CG27 & Cotton bolls & Oblong & $10.42 \mathrm{c}$ & $3.21 \mathrm{ab}$ & A & $6.27 \mathrm{a}$ & $78.28 \mathrm{~d}$ & $54.07 \mathrm{f}$ \\
\hline HUCG-103 & Cotton bolls & Oblong & $10.22 \mathrm{de}$ & $2.80 \mathrm{gh}$ & B & $4.67 \mathrm{ij}$ & $85.28 \mathrm{c}$ & $74.26 \mathrm{e}$ \\
\hline CG06 & Leaves & Oval & $9.73 \mathrm{j}$ & $2.73 \mathrm{ijkl}$ & B & $4.77 \mathrm{~h}$ & $80.33 \mathrm{~cd}$ & $52.76 \mathrm{f}$ \\
\hline CG10 & Leaves & Oval & $9.90 \mathrm{hi}$ & $2.79 \mathrm{ghi}$ & B & 4.321 & $17.85 \mathrm{fg}$ & $8.25 \mathrm{~g}$ \\
\hline CG12 & Leaves & Oval & $10.07 \mathrm{efgh}$ & 2.77 ghij & $\mathrm{C}$ & $4.61 \mathrm{jk}$ & $164.3 \mathrm{a}$ & $144.28 \mathrm{bcd}$ \\
\hline CG13 & Leaves & Oval & $9.95 \mathrm{a}$ & $2.73 \mathrm{ijkl}$ & B & $4.11 \mathrm{n}$ & $5.1 \mathrm{~h}$ & $10.34 \mathrm{~g}$ \\
\hline CG14 & Leaves & Oval & $10.52 \mathrm{abc}$ & $3.23 \mathrm{ab}$ & A & $6.27 \mathrm{a}$ & $168.02 \mathrm{a}$ & $137.47 \mathrm{~cd}$ \\
\hline CG15 & Leaves & Oval & $10.21 \mathrm{de}$ & $2.81 \mathrm{fg}$ & A & $6.27 \mathrm{a}$ & $12.73 \mathrm{~g}$ & $10.09 \mathrm{~g}$ \\
\hline CG17 & Leaves & Oval & $10.23 \mathrm{de}$ & $2.81 \mathrm{fg}$ & A & $6.27 \mathrm{a}$ & 23.77 ef & $18.74 \mathrm{~g}$ \\
\hline CG18 & Leaves & Oval & $10.03 \mathrm{fgh}$ & $2.97 \mathrm{~d}$ & $\mathrm{D}$ & $5.51 \mathrm{e}$ & $166.96 \mathrm{a}$ & $154.6 \mathrm{abc}$ \\
\hline CG19 & Leaves & Oval & $10.41 \mathrm{c}$ & 2.76 ghijk & A & $6.27 \mathrm{a}$ & $12.19 \mathrm{~g}$ & $12.25 \mathrm{~g}$ \\
\hline CG08 & Leaves & Fusiform & 10.17 ef & $2.80 \mathrm{gh}$ & $\mathrm{C}$ & $5.60 \mathrm{~d}$ & $78.37 \mathrm{~d}$ & $49.08 \mathrm{f}$ \\
\hline
\end{tabular}

\footnotetext{
$\mathrm{v}^{\mathrm{v}}$ The mean difference between each group is significant at the 0.05 level; based on Tukey's test, values with the same lowercase letters within a column do not differ significantly.

${ }^{\mathrm{w}}$ AUDPC $=$ area under the disease progress curve-days; Susc $=$ susceptible and Res $=$ resistant.

${ }^{x}$ Colletotrichum gossypii isolates are arranged on the basis of their conidial shape: Oblong $=$ oblong elliptical, Oval $=$ oval elliptical, and Fusiform $=$ elliptical fusiform.

y A = gray colony, cottony texture, high density, sectors absent, irregular edges; $\mathrm{B}=$ pinkish- to grayish-white colony, fructification present in the colony center, cottony texture, sectors absent, high density, uniform edges; $\mathrm{C}=$ grayish-white colony, fructification present all over the colony surface, velvety texture, high density, sectors present, uniform edges; $\mathrm{D}=$ yellowish-whitish color, fructification present in the colony center, cottony texture, high density, sectors absent, uniform edges; $\mathrm{E}$ = light-grayish colony, abundant fructification rings throughout the colony, velvety texture, intermediate density, sectors absent, uniform edges.

${ }^{\mathrm{z}}$ Growth rate (diameter of colonies in millimeters per day) on potato dextrose agar was measured daily from the 5th day to 20 th day after inoculation.
} 
across the colony or grouped together in bands or rows. Microscopic observations revealed that the unitunicate asci had delicate walls and eight ascospores per ascus. The unicellular ascospores were hyaline, ellipsoidal, and slightly curved. Statistical analyses of the qualitative variables indicated phenotypic variability among the isolates.

Among the 27 C. gossypii isolates, isolate CG06 showed the most morphological and growth variability and CG19 showed the least (Table 2). Significant differences $(P<0.05)$ in the growth rate of isolates were observed. Isolates were classified as having high, intermediate, or low growth rate based on the extent of growth. Isolates CG01, CG09, CG12, CG14, CG22, and CG26 exhibited high growth rates (6.0 to $7.1 \mathrm{~mm}$ day $^{-1}$ ); isolates CG04, CG11, CG16, CG18, CG21, CG23, CG25, and CG27 showed intermediate growth rates (3.9 to $5.9 \mathrm{~mm} \mathrm{day}^{-1}$ ); and isolates CG07, CGCG10, CG13, CG15, CG17, CG19, and CG24 showed low growth rates (1.3 to $4.0 \mathrm{~mm}$ day $^{-1}$ ). The morphological features of the isolates of $C$. gossypii were compared with those of the reference strain HUCG-103. Morphological data for HUCG-103 are shown in Table 2.

Pathogenicity tests. Cotton leaves artificially inoculated with C. gossypii developed symptoms that were typical of anthracnose. Reddish-brown lesions appeared at the start of the infection and turned violet-black as the infection became severe. The size of the lesions also increased in size around the inoculation point. Between 15 and 25 days after inoculation, sporulation occurred profusely as the lesions matured. The control leaves did not develop any symptoms of disease. Significantly different levels of virulence $(P<0.05)$ were found between some of the isolates. Most of the $C$. gossypii isolates caused disease in leaves of both the resistant and susceptible cultivars. The resistant and susceptible cultivars that had been inoculated with CG01, CG05, CG09, CG12, CG14, or CG18 showed symptoms within 5 days of inoculation, whereas symptoms developed more slowly when leaves were inoculated with other isolates. Leaves of the resistant cultivar inoculated with CG02, CG04, CG13, CG14, CG15, CG17, CG22, CG24, CG26, or CG27 isolates developed symptoms more slowly than the leaves of the susceptible cotton cultivar. Leaves of the susceptible cultivar inoculated with isolates CG04, CG17, or CG22 also developed symptoms of disease more rapidly than the resistant cultivar. However, both resistant and susceptible cultivars developed a few symptoms at the same time when inoculated with CG02, CG15, CG20, or CG24. Leaves of resistant and susceptible cultivars inoculated with the other $C$. gossypii isolates showed mild symptoms. Virulence of the C. gossypii isolates was evaluated using the AUDPC-days scores (Table 2). Isolates CG01, CG09, and CG26 were the most virulent and were significantly more virulent $(P<$ $0.05)$ against susceptible and resistant cultivars than the reference strain HUCG-103, whereas CG02, CG10, CG15, CG19, and CG24 were the least virulent of the 27 isolates and significantly less virulent $(P<0.05)$ than HUCG-103 (Table 2; Fig. 1).

Molecular identification. The primer pairs ITS1 and ITS4, TUB5 and TUB6, and GAP1 and GAP4 successfully amplified the ITS, TUB, and GAPDH regions, respectively, of the 27 isolates. BLAST analysis of the sequences obtained revealed a high level of similarity (98 to 100\%) between the ITS, TUB, and GAPDH regions of the 27 isolates identified as $C$. gossypii and other Colletotrichum spp.

Sequence variation in the TUB region and design of $C$. gossypiispecific primers. Species-specific primers were designed using the TUB gene sequence. A comparison of the TUB gene sequences of 77 Colletotrichum isolates deposited in GenBank and our 27 C. gossypii isolates revealed that the TUB gene of all these isolates showed more than $97 \%$ similarity and that there were only singlenucleotide differences between them. For this reason, we focused only on the single-nucleotide sequence. We tried to find a position in the sequence where all C. gossypii isolates (i.e., our 27 C. gossypii isolates and the C. gossypii isolates obtained from GenBank) showed $100 \%$ similarity with each other but no similarity with other Colletotrichum spp. We found the desired nucleotide alignment at position 98 to 101 (Supplementary Fig. S2). The single-nucleotide polymorphism (SNP) difference was placed at the $5^{\prime}$ end of the forward primer SPSCG/F. The SNP used to design the primer pair is part of the start codon but is missing in members of other species belonging to the Colletotrichum genus. This SNP-based primer set amplified only $C$. gossypii and was a reliable diagnostic assay for identifying $C$. gossypii. The SPSCG/F and SPSCG/R primer pair amplified a product of approximately $294 \mathrm{bp}$ when used to amplify C. gossypii isolates.

Specificity of species-specific primers. The SPSCG/F and SPSCG/R primer pair were specifically designed to amplify $C$. gossypii. To test the specificity of these primers, we attempted to amplify species that belonged to the $C$. gloeosporioides species complex other than C. gossypii and to amplify other fungal genera; however, amplification failed (Table 1). This result was consistently obtained in repeated experiments.

Sensitivity of species-specific primers. The primers reliably detected $C$. gossypii DNA in mixtures that also contained $C$. gloeosporioides or $C$. fructicola DNA, even when the amount of $C$. gossypii DNA in the mixture was up to 10 times lower than that of the other species (Supplementary Fig. S1). After gel electrophoresis, a strong band was observed indicating the amplification of $C$. gossypii PCR product in a 1:10 mixture comprising $1.067 \mathrm{ng}$ of $C$. gossypii DNA and $10.685 \mathrm{ng}$ of C. fructicola DNA, and in a 1:10 mixture comprising $1.067 \mathrm{ng}$ of C. gossypii DNA and $10.940 \mathrm{ng}$ of $C$. gloeosporioides DNA. The PCR assay detected $C$. gossypii at concentrations as low as $10 \mathrm{pg}$ of pure genomic DNA. In the control treatment, only $C$. gossypii DNA was amplified; attempts to amplify $C$. gloeosporioides, $C$. fructicola, or deionized sterilized water failed to produce a band, indicating that amplification had failed. The same results were obtained when the experiment was repeated.

DNA modeling and phylogenetic analysis. Different DNA models were examined based on their Akaike information criterion, BIC, maximum likelihood values $(I n L)$, and nucleotide frequencies. The $\mathrm{K} 2$ model was found to be the best model for phylogenetic analysis of the DNA sequence of the C. gossypii TUB region because it attained the lowest BIC value $(2,222.42)$ with the best substitution pattern. Two phylogenetic consensus trees were developed on the basis of Bayesian inference and the bootstrap technique. The first maximum-likelihood tree was constructed using the TUB sequences of the 27 C. gossypii isolates from China and TUB sequences of isolates belonging to the $C$. gloeosporioides species complex that were obtained from GenBank (Fig. 2). The second maximum-likelihood tree was constructed using the TUB sequences of the 27 C. gossypii isolates from China and TUB sequences of $C$. gossypii obtained from GenBank (Fig. 3). The first phylogenetic tree had the highest log likelihood value of $-1,223.2956$ (Fig. 2). In the C. gloeosporioides clade, Colletotrichum spp. with accession numbers KU318707.1 and KP716993.1 and C. simmondsii with accession number KT957918.1 were considered outgroups and their genetic distance from other members of this tree was 0.0435 . The second tree was constructed to show the phylogenetic relationships among the 27 Chinese $C$. gossypii isolates and the GenBank C. gossypii isolates (Fig. 3). Specifically, the horizontal dimension of this maximum-likelihood tree showed the extent of the genetic change among the $C$. gossypii isolates analyzed. The tree shows that the TUB gene region of all the $C$. gossypii isolates had the same genetic makeup, with minor evolution. The log-likelihood value of this maximum-likelihood phylogenetic tree was -600.1722 (Fig. 3). These two trees (Figs. 2 and 3) demonstrate that isolates belonging to the C. gloeosporioides species complex do not have large molecular differences; however, their pathogenicity, host specification, proteins, and gene expression depend on single-nucleotide differences. Hence, SNP were used to design species-specific primers to identify C. gossypii.

\section{Discussion}

Our observations of the 27 C. gossypii isolates isolated from three provinces in China revealed that they showed the same morphological and cultural characteristics as those previously reported for C. gossypii (Shamsi et al. 2015). Furthermore, our C. gossypii isolates produced typical symptoms of anthracnose when they were used to inoculate cotton leaves (Table 2; Fig. 1). We also observed that young leaves were more susceptible to disease than older leaves, which supports the observations reported by Álvarez et al. (2014).

C. gossypii belongs to the C. gloeosporioides species complex and forms a phylogenetic lineage within the $C$. gloeosporioides species 
complex (Salustiano et al. 2014). Therefore, we constructed two phylogenetic lineage trees based on the sequences of the TUB gene. The phylogenetic lineage shown in Figures 2 and 3 reveals that the C. gossypii isolates collected from China and the C. gossypii GenBank isolates fall into the same clade and show the least genetic divergence from the other species belonging to the $C$. gloeosporioides species complex (Weir et al. 2012). Two isolates of $C$. gossypii have been identified in Brazil and Bolivia using short sequences from the rRNA gene region (Dinh et al. 2003). Previous reports suggest that C. gossypii var. cephalosporioides and C. gossypii are two separate lineages but with only a short sequence divergence, and are considered as cospecific with C. gloeosporioides (Kirkpatrick and Rothrock

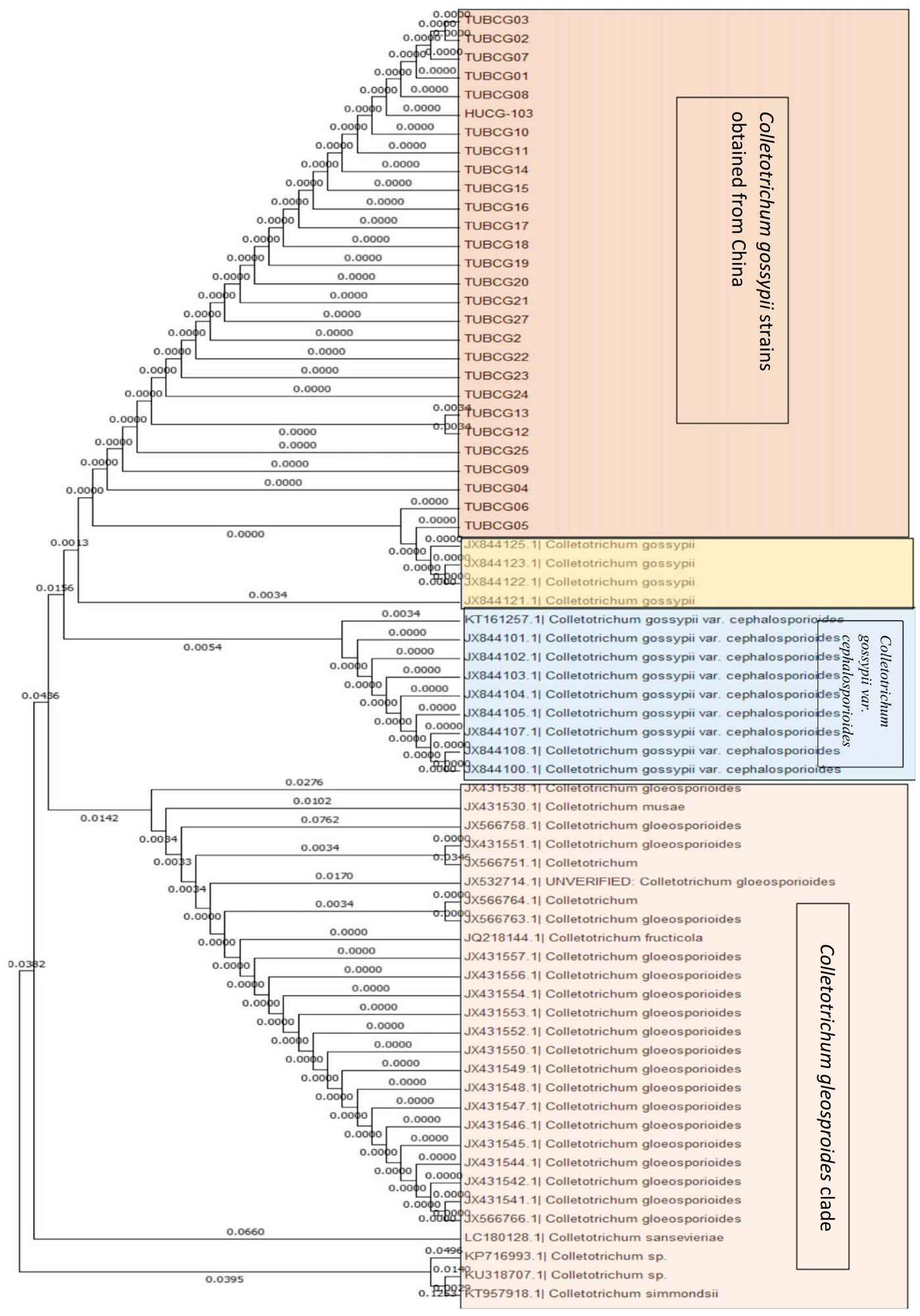

Fig. 2. Phylogenetic consensus tree based on Bayesian inference, illustrating the relationships between the strains within the Colletotrichum gloeosporioides species complex. The C. gossypii strains isolated from diseased cotton plants in China are labeled TUBCG01 to TUBCG27 and the genus and species name of the GenBank sequences are shown. Numbers above the branches indicate the phylogenetic relationship in terms of branch length. The tree was constructed using $\beta$-tubulin gene sequence data. Colletotrichum simmondsii (KT957918.1), Colletotrichum spp. (KU318707.1), and Colletotrichum spp. (KP716993.1) were used as outgroups. The tree with the highest log likelihood value is $-1,223.2956$ 
2001). This low level of genetic divergence has made it difficult to screen out $C$. gossypii from other species of the $C$. gloeosporioides species complex (Weir et al. 2012).

Traditionally, the process of identifying $C$. gossypii from diseased plant tissues has been laborious and unreliable. Furthermore, considerable experience is required to discriminate Colletotrichum spp. on the basis of their morphology because of many complicating factors relating to their morphological appearance among diverse species (Phoulivong et al. 2012). The need to overcome these difficulties led to a demand for the development of other diagnostic methods that were more reliable, rapid, and species-specific, such as PCR, enzyme-linked immunosorbent assay, and real-time PCR. In 2005, Silva-Mann et al. (2005) distinguished C. gossypii var. cephalosporioides from $C$. gossypii isolates using amplified fragment length

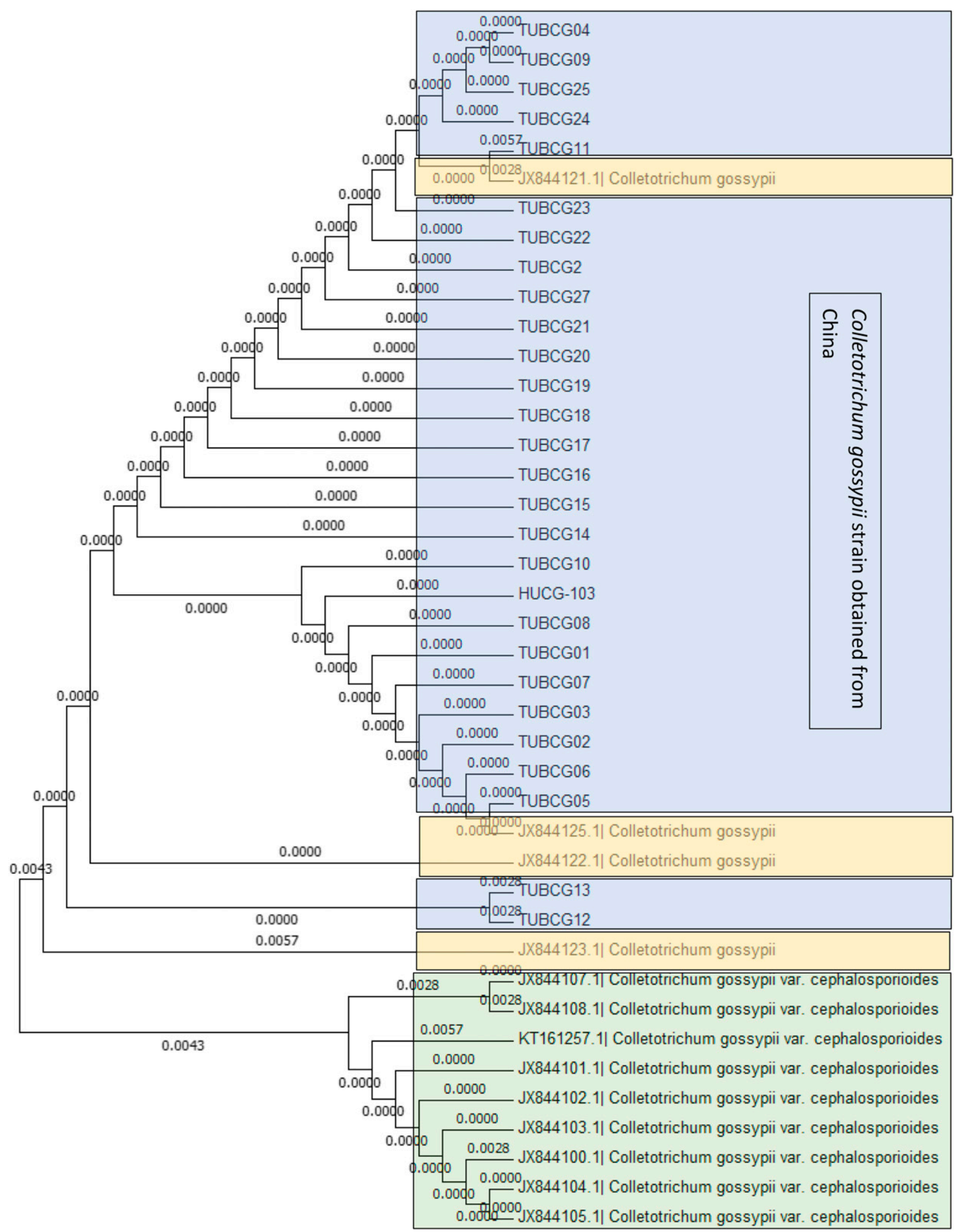

Fig. 3. Maximum-likelihood phylogram inferred from partial $\beta$-tubulin (TUB) sequence data showing the phylogenetic relationship between Colletotrichum gossypii strains isolated from diseased cotton plants (Gossypium hirsutum) in China (TUBCG01 to TUBCG27) and all of the available C. gossypii and C. gossypii var. cephalosporioides sequences obtained from GenBank. Genus and species names of the GenBank sequences are shown. Numbers above the branches indicate the phylogenetic relationship among the isolates in terms of branch length. The tree with the highest log likelihood value is -600.1722 (Cannon et al. 2012). 
polymorphisms marker but this method could not accommodate the ambiguity arising in identification. The low levels of genetic diversity among Colletotrichum spp. required the design of primers that targeted SNP (Nussberger et al. 2013). To address all these issues, we have designed a rapid, sensitive, and reliable method for detecting $C$. gossypii. We have developed a species-specific primer pair, SPSCG/F and SPSCG/R, to amplify the TUB gene of $C$. gossypii, generating an amplification product of approximately $294 \mathrm{bp}$. These PCR primers provide a rapid means of discriminating $C$. gossypii from other species complexes, thereby enabling the precise identification and surveillance of the pathogen in different hosts and locations. To our knowledge, C. gossypii-specific primers have not been reported previously. The development of this PCR method has significant practical applications. Given that the diverse genus of Colletotrichum reacts in different ways to the same control strategy (Mahuku 2004), the timely and reliable identification of diseased plants would assist pathogen identification, enabling more effective control processes for both pre- and postharvest crops. Moreover, anthracnose in cotton reported in different regions of the world, including Europe, has mainly been linked with $C$. gossypii (Hyde et al. 2009). These disease management issues reinforce the importance of using species-specific primer sets in diagnostics.

Primers SPSCG/F and SPSCG/R were designed using the TUB gene sequence regions. These regions are useful for assessing close genealogical affiliations because they show a high level of interspecies variance. In this study, we demonstrated that $C$. gossypii could be detected at concentrations as low as $10 \mathrm{pg}$ of pure genomic DNA using conventional PCR. Owing to its sensitivity and specificity, this C. gossypii-specific primer set should specifically amplify only this pathogen from fungal structures or diverse tainted tissues at immature stages of infection when only the initial symptoms of disease have appeared. Another advantage of this species-specific primer set is the speed of the diagnostic process because there is no need to isolate and cultivate the fungus to identify it.

In some cotton-producing areas, anthracnose is more devastating because the pathogen has developed a high level of resistance to the fungicides that are used (Cai et al. 2009). Rapid identification and monitoring of different Colletotrichum spp. at various growth stages of the crop would aid in recognition of the prevalent species and enable the application of effective control methods (Pileggi et al. 2009). This rapid detection assay should provide the agricultural industry with a tool to avoid high-risk situations and apply a rational selection of fungicides to control anthracnose in different crops.

\section{Acknowledgments}

We thank the Cotton Research Institute Sanya, Hainan, China, and local farmers for their help with the collection of samples; and our colleagues for many helpful and motivating discussions.

\section{Literature Cited}

Afanador-Kafuri, L., González, A., Gañán, L., Mejía, J. F., Cardona, N., and Alvarez, E. 2014. Characterization of the Colletotrichum species causing anthracnose in Andean blackberry in Colombia. Plant Dis. 98:1503-1513.

Afanador-Kafuri, L., Minz, D., Maymon, M., and Freeman, S. 2003. Characterization of Colletotrichum isolates from tamarillo, passiflora, and mango in Colombia and identification of a unique species from the genus. Phytopathology 93:579-587.

Álvarez, E., Gañán, L., Rojas-Triviño, A., Mejía, J. F., Llano, G. A., and González, A. 2014. Diversity and pathogenicity of Colletotrichum species isolated from soursop in Colombia. Eur. J. Plant Pathol. 139:325-332.

Araújo, A. E., Suassuna, N. D., Farias, F. J. C., and Freire, E. C. 2003. Escalas de Notas Para Avaliação de Doenças Foliares do Algodoeiro. In: Congresso Brasileiro de Algodão, Goiânia anais campina grande (CD-ROM). Embrapa Algodão, Brasilia, Brazil.

Botero, M. J., and Franco, G. 2008. Identificación y caracterización preliminar del agente causal de la mancha necrótica de las hojas de la mora (Rubus glaucus) en el muncipio de Trujillo (Valle del Cauca, Colombia). Cienc. Tecnol. Agropecu. 8:22-25.

Cai, L., Hyde, K. D., Taylor, P. W. J., Weir, B. S., Waller, J. M., Abang, M. M., Zhang, J. Z., Yang, Y. L., Phoulivong, S., Liu, Z. Y., Prihastuti, H., Shivas,
R. G., McKenzie, E. H. C., and Johnston, P. R. 2009. A polyphasic approach for studying Colletotrichum. Fungal Divers. 39:183-204.

Cannon, P. F., Damm, U., Johnston, P. R., and Weir, B. S. 2012. Colletotrichum current status and future directions. Stud. Mycol. 73:181-213.

Carbone, I., and Kohn, L. M. 1999. A method for designing primer sets for speciation studies in filamentous Ascomycetes. Mycologia 91:553-556.

Damm, U., Woudenberg, J. H. C., Cannon, P. F., and Crous, P. W. 2009. Colletotrichum species with curved conidia from herbaceous hosts. Fungal Divers. 39:45-87.

Dinh, S. Q., Chongwungse, J., Pongam, P., and Sangchote, S. 2003. Fruit infection by Colletotrichum gloeosporioides and anthracnose resistance of some mango cultivars in Thailand. Australas. Plant Pathol. 32:533-538.

Emge, R. G., and Shrum, R. D. 1976. Epiphytology of Puccinia striiformis at five selected locations in Oregon during 1968 and 1969. Phytopathology 66: 1406-1412.

Hübschen, J., Kling, L., Ipach, U., Zinkernagel, V., Bosselut, N., Esmenjaud, D., Brown, D. J. F., and Neilson, R. 2004. Validation of the specificity and sensitivity of species-specific primers that provide a reliable molecular diagnostic for Xiphinema diversicaudatum, X. index and X. vuittenezi. Eur. J. Plant Pathol. 110:779-788.

Hyde, K. D., Cai, L., Cannon, P. F., Crouch, J. A., Crous, P. W., Damm, U., Goodwin, P. H., Chen, H., Johnston, P. R., Jones, E. B. G., Liu, Z. Y., McKenzie, E. H. C., Moriwaki, J., Noireung, P., Pennycook, S. R., Pfenning, L. H., Prihastuti, H., Sato, T., Shivas, R. G., Tan, Y. P., Taylor, P. W. J., Weir, B. S., Yang, Y. L., and Zhang, J. Z. 2009. Colletotrichum-Names in current use. Fungal Divers. 39:147-182.

Kirkpatrick, T. L., and Rothrock, C. S., eds. 2001. Compendium of Cotton Diseases, 2nd ed. American Phytopathological Society, St. Paul, MN.

Kück, P., and Meusemann, K. 2010. FASconCAT: Convenient handling of data matrices. Mol. Phylogenet. Evol. 56:1115-1118.

Lima, J. S., Figueiredo, J. G., Gomes, R. G., Stringari, D., Goulin, E. H., Adamoski, D., Kava-Cordeiro, V., Galli-Terasawa, L. V., and Glienke, C. 2012. Genetic diversity of Colletotrichum spp. an endophytic fungi in a medicinal plant, Brazilian pepper tree. ISRN Microbiol. 2012: Article ID 215716.

Mahuku, G. S. 2004. A simple extraction method suitable for PCR-based analysis of plant, fungal, and bacterial DNA. Plant Mol. Biol. 22:71-81.

Nussberger, B., Greminger, M. P., Grossen, C., Keller, L. F., and Wandeler, P. 2013. Development of SNP markers identifying European wildcats, domestic cats, and their admixed progeny. Mol. Ecol. Resour. 13:447-460.

O'Donnell, K., and Cigelnik, E. 1997. Two divergent intragenomic rDNA ITS2 types within a monophyletic lineage of the fungus Fusarium are nonorthologous. Mol. Phylogenet. Evol. 7:103-116.

Phoulivong, S., Cai, L., Chen, H., McKenzie, E. H. C., Abdelsalam, K., Chukeatirote, E., and Hyde, K. D. 2010. Colletotrichum gloeosporioides is not a common pathogen on tropical fruits. Fungal Divers. 44:33-43.

Phoulivong, S., McKenzie, E. H. C., and Hyde, K. D. 2012. Cross infection of Colletotrichum species; a case study with tropical fruits. Curr. Res. Environ. Appl. Mycol. 2:99-111.

Pileggi, S. A. V., Vieira de Oliveira, S. F., Andrade, C. W., Vicente, V. A., do Rocio Dalzoto, P., da Cruz, G. K., Gabardo, J., Massola, N. S., Tozze, H. J., Pileggi, M., Kava-Cordeiro, V., Galli-Terasawa, L. V., Pimentel, I. C., Stringari, D. and Glienke, C. 2009. Molecular and morphological markers for rapid distinction between 2 Colletotrichum species. Can. J. Microbiol. 55: 1076-1088.

Ronquist, F., Teslenko, M., Van Der Mark, P., Ayres, D. L., Darling, A., Hohna, S., Larget, B., Liu, L., Suchard, M. A., and Huelsenbeck, J. P. 2012. MrBayes 3.2: Efficient Bayesian Phylogenetic Inference and Model Choice Across a Large Model Space. Syst. Biol. 61:539-542.

Salustiano, M. E., Rondon, M. N., Abreu, L. M., da Silva Costa, S., da Cruz Machado, J., and Pfenning, L. H. 2014. The etiological agent of cotton ramulosis represents a single phylogenetic lineage within the Colletotrichum gloeosporioides species complex. Trop. Plant Pathol. 39:357-367.

Shamsi, S., Naher, N., and Azad, R. 2015. Mycoflora of cotton plant (Gossypium hirsutum L.) - With three new records of deuteromycetes from Bangladesh. J. Bangladesh Acad. Sci. 39:213-221.

Silva-Mann, R., Vieira, M. G. G. C., Machado, J. C., Bernardino Filho, J. R. Salgado, K. C. C., and Stevens, M. R. 2005. AFLP markers differentiate isolates of Colletotrichum gossypii from C. gossypii var. cephalosporioides. Fitopatol. Bras. 30:169-172.

Tamura, K., Stecher, G., Peterson, D., Filipski, A., and Kumar, S. 2013. MEGA6: Molecular evolutionary genetics analysis version 6.0. Mol. Biol. Evol. 30: 2725-2729.

Templeton, D., Rikkerink, E. H. A., Solon, S. L., and Crowhurst, R. N. 1992. Cloning and molecular characterization of the glyceraldehyde-3-phosphate dehydrogenase-encoding gene and cDNA from the plant pathogenic fungus Glomerella cingulata. Horticulture 122:225-230.

Weir, B. S., Johnston, P. R., and Damm, U. 2012. The Colletotrichum gloeosporioides species complex. Stud. Mycol. 73:115-180. 